\title{
Dapsone Resistance in Leprosy Patients Originally from American Samoa, United States, 2010-2012
}

\section{Diana L. Williams, Sergio Araujo, Barbara M. Stryjewska, David Scollard}

Author affiliations: Louisiana State University School of Veterinary Medicine, Baton Rouge, Louisiana, USA (D.L. Williams); Centro de Referência Nacional em Hanseníase/Dermatológica Sanitária, Uberlândia, Brazil (S. Araujo); National Hansen's Disease Programs, Baton Rouge, Louisiana, USA (D.L. Williams, S. Araujo, B.M. Stryjewska, D. Scollard)

DOI: https://doi.org/10.3201/eid2408.180033

Skin biopsies from US leprosy patients were tested for mutations associated with drug resistance. Dapsone resistance was found in 4 of 6 biopsies from American Samoa patients. No resistance was observed in patients from other origins. The high rate of dapsone resistance in patients from American Samoa warrants further investigation.

$\mathrm{S}$ tandard treatment for leprosy is multidrug therapy with dapsone, rifampin, and clofazimine (1). Resistance to dapsone and rifampin has been observed in many leprosyendemic regions of the world (2-5). The Global Sentinel Surveillance for Drug Resistance in Leprosy program was established by the World Health Organization to monitor global leprosy drug resistance among cases of relapse (6). With this program, 9 cases of dapsone resistance and 1 case of rifampin resistance were found among 72 leprosy relapse patients from 8 participating countries in 2010 (7). However, some leprosy-endemic countries and countries with low incidence, such as the United States ( $\approx 200$ cases/y), are not involved in this program, even though most US patients with leprosy migrated from endemic areas where drug resistance has been identified (8).

Previously, we performed a survey of drug resistance among US leprosy patients referred to the National Hansen's Disease Programs (Baton Rouge, Louisiana, USA) during 2010-2012 (8). Of 39 patients with origins in the Pacific Islands $(n=18)$, Central or South America $(n=5)$, Asia $(\mathrm{n}=2)$, and the United States $(\mathrm{n}=14), 1$ patient had dapsone-resistant Mycobacterium leprae and 1 had dapsone- and rifampin-resistant M. leprae (9). Both of these cases originated in American Samoa.

We expanded this previous survey by evaluating an additional 11 US leprosy patients from American Samoa and US patients from other geographic origins for susceptibility to dapsone and rifampin. All specimens had been referred to the National Hansen's Disease Programs for histopathologic diagnosis and were tested by using previously published molecular drug susceptibility protocols (6). We were able to obtain susceptibility results for only 4 of the $11 \mathrm{US}$ patients from American Samoa. Mutations in folP1, a gene associated with dapsone resistance (4), were detected in 2 of these patients; no drug resistance was observed in US patients from other origins (Table). Combining these results with our previously published data, 4 of 6 US patients from American Samoa had dapsone-resistant M. leprae, and 1 of these was also resistant to rifampin. All 4 dapsone-resistant isolates had distinct mutations (P55L, P55R, $\mathrm{T} 53 \mathrm{I}$, and $\mathrm{T} 53 \mathrm{~A}$ ) in the drug resistance-determining region of the M. leprae folP 1 gene. The data strongly suggest that these M. leprae isolates are not clonal in origin (i.e., did not originate from a single dapsone-resistant clone). In addition, all patients with resistance seemed to have primary resistance to dapsone because biopsies were taken before known treatment with antileprosy drugs.

The registry of the National Hansen's Disease Programs indicates that 23 patients from American Samoa were given leprosy diagnoses in the United States during 2002-2014. Because of insufficient DNA or specimen unavailability, drug susceptibility of only 6 patients could be determined. Findings indicate that at least $4(17 \%)$ of these 23 patients were infected with dapsone-resistant M. leprae. Biopsy results of 20 US leprosy patients known to be originally from other locations given diagnoses during this time interval did not demonstrate dapsone or rifampin resistance. Eleven (55\%) of these patients had Pacific Island origins.

Dapsone resistance in American Samoa could have developed before implementation of multidrug therapy in this population, when dapsone was used as a monotherapy for leprosy. Several patients from American Samoa indicated that frequent visits occur between friends and relatives in American Samoa and Western Samoa; however, no information is currently available regarding drug resistance in Western Samoa.

Dapsone resistance might not necessarily have clinical significance when patients take multidrug therapy as recommended by the World Health Organization. However, in patients with a high bacteria load, resistance to dapsone essentially results in dual therapy with rifampin and clofazimine, placing the burden on just 2 drugs in the multidrug therapy regimen. Moreover, in this regimen, rifampin is taken only once monthly, so the patient is receiving only 1 effective drug (clofazimine) daily. In addition, patient noncompliance might result in the selection of multidrug-resistant $M$. leprae. In another study, resistance to dapsone and rifampin was found in 1 of 4 dapsone-resistant cases, with the 1 case occurring in a relapse patient (9). Therefore, $M$. leprae drug resistance (including the identification and evaluation of new markers for dapsone resistance) should be further studied in 
Table. Drug resistance in leprosy patients with and without origins in American Samoa, USA, 2012-2015*

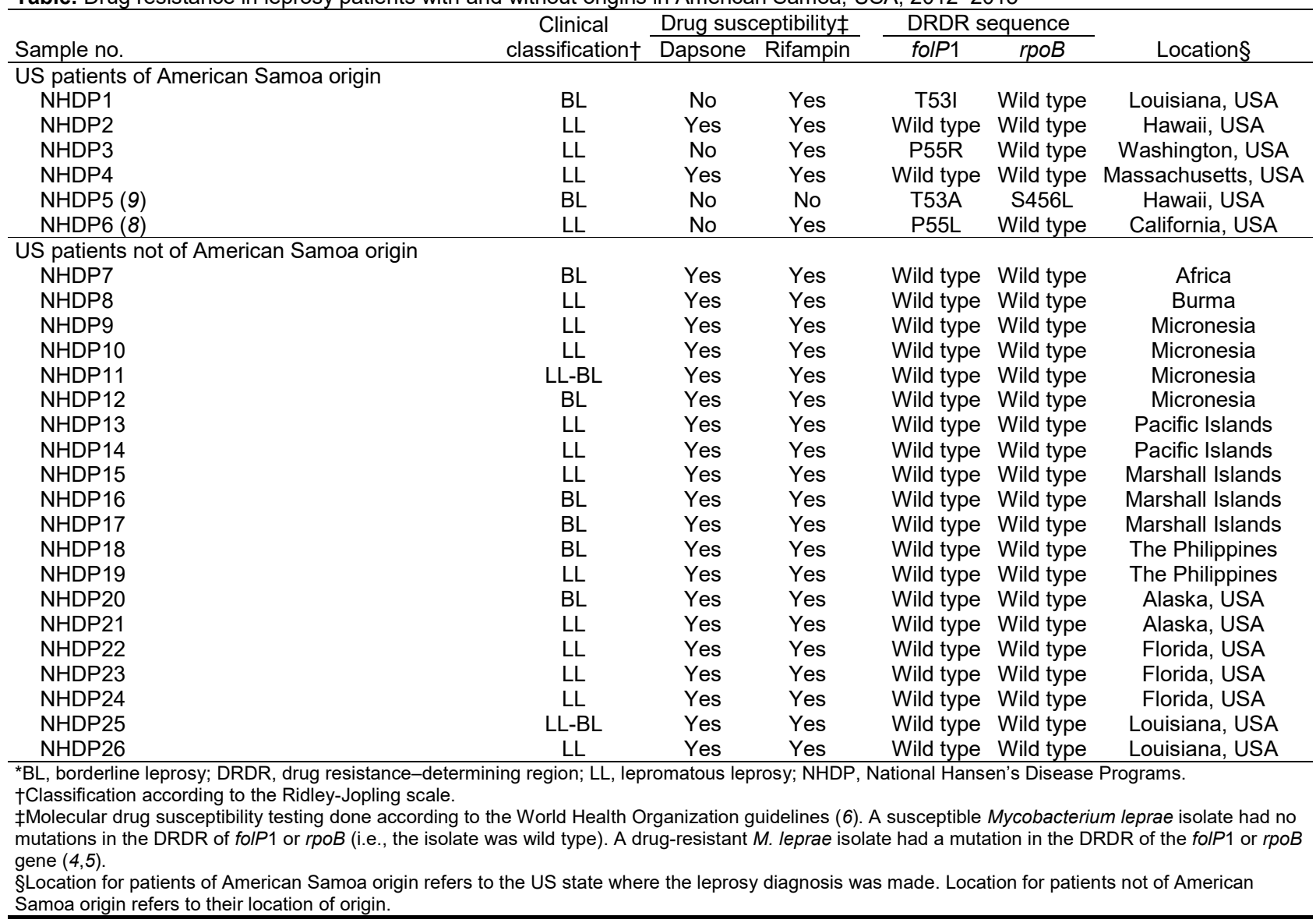

the American Samoa population (5). This research will most likely require correlation of epidemiologic, clinical, and molecular drug susceptibility data from a large number of leprosy patients in this leprosy-endemic region (10).

\section{About the Author}

Dr. Williams is an adjunct associate professor of pathobiological sciences at Louisiana State University School of Veterinary Medicine in Baton Rouge, Louisiana, USA. She is a molecular biologist retired from the Laboratory Research Branch of the National Hansen's Disease Programs. Her research interests include the study of the molecular biology of mycobacterial pathogens.

\section{References}

1. World Health Organization Study Group on Leprosy for Control Programmes. Chemotherapy of leprosy for control programmes: report of a WHO study group [meeting held in Geneva from 12 to 16 October 1981]. Geneva: World Health Organization; 1982 [cited 2018 Jan 8]. http://www.who.int/iris/handle/10665/38984

2. Cambau E, Perani E, Guillemin I, Jamet P, Ji B. Multidrugresistance to dapsone, rifampicin, and ofloxacin in Mycobacterium leprae. Lancet. 1997;349:103-4. http://dx.doi.org/10.1016/ S0140-6736(05)60888-4
3. Matsuoka M. Drug resistance in leprosy. Jpn J Infect Dis. 2010;63:1-7.

4. Williams DL, Gillis TP. Drug-resistant leprosy: monitoring and current status. Lepr Rev. 2012;83:269-81.

5. Benjak A, Avanzi C, Singh P, Loiseau C, Girma S, Busso P, et al. Phylogenomics and antimicrobial resistance of the leprosy bacillus Mycobacterium leprae. Nat Commun. 2018;9:352. http://dx.doi.org/10.1038/s41467-017-02576-z

6. World Health Organization. Guidelines for global surveillance of drug resistance in leprosy. New Delhi (India): The Organization; 2009 [cited 2018 Jan 8]. http://www.searo.who.int/entity/global leprosy_programme/publications/guide_surv_drug_res_2009.pdf

7. World Health Organization. Surveillance of drug resistance in leprosy: 2010. Wkly Epidemiol Rec. 2011;86:237-40.

8. Williams DL, Lewis C, Sandoval FG, Robbins N, Keas S, Gillis TP, et al. Drug resistance in patients with leprosy in the United States. Clin Infect Dis. 2014;58:72-3. http://dx.doi.org/ 10.1093/cid/cit628

9. Williams DL, Hagino T, Sharma R, Scollard D. Primary multidrugresistant leprosy, United States. Emerg Infect Dis. 2013;19:179-81. http://dx.doi.org/10.3201/eid1901.120864

10. World Health Organization. Epidemiological review of leprosy in the WHO Western Pacific Region, 2000. Manila (Philippines): The Organization; 2002 [cited 2018 Jan 8]. http://www.wpro.who.int/ leprosy/documents/leprosy_review_2000.pdf p.3

Address for correspondence: Diana L. Williams, National Hansen's Disease Programs, Laboratory Research Branch, SVM-LSU, Rm 3517, Skip Bertman Dr, Baton Rouge, LA 70817, USA; email: dnarna21@aol.com 